\title{
Impact of Friedreich's Ataxia on health-care resource utilization in the United Kingdom and Germany
}

\author{
Paola Giunti ${ }^{*}$, Julia Greenfield ${ }^{2}$, Alison J Stevenson², Michael H Parkinson', Jodie L Hartmann³,
} Ruediger Sandtmann ${ }^{4}$, James Piercy ${ }^{5}$, Jamie O'Hara ${ }^{5}$, Leo Ruiz Casas ${ }^{5}$ and Fiona M Smith ${ }^{5}$

\begin{abstract}
Background: Friedreich's Ataxia (FRDA) is a neurodegenerative disorder that causes progressive damage to the central and peripheral nervous systems having a significant impact upon quality of life. With little information in the literature, cross-sectional observational studies were conducted in the UK and Germany to collect data on resource use and the burden of the disease on individuals and their caregivers.

Methods: Cross-sectional observational studies were conducted in the UK and Germany to estimate the burden of FRDA on individuals and on the respective healthcare systems. A total of 75 individuals in the UK and 28 in Germany were recruited to the study. Participants in both countries were asked to complete a Patient and Caregiver Information Form (PCIF), regarding access to, and use of, healthcare resources, and the impact FRDA has on their lifestyle. In Germany, doctors were asked to complete a Patient Record Form (PRF). Analyses of annual direct and indirect resource utilization were conducted for both countries while costs were calculated for the UK only. These figures were compared to the costs associated with Parkinson's disease; one of the most common neurodegenerative conditions and the one most similar in terms of disease progression.
\end{abstract}

Results: The results showed that the annual burden of FRDA is significant and falls on the health and social care sectors, on society, on caregivers and on the individuals themselves. In the UK FRDA had a total annual cost per person of between $£ 11,818$ and $£ 18,774$ depending on whether the cost of long-term unemployment was included.

Typically the largest component of direct costs is associated with professional care. Given the high proportion of children and young adults recruited and the long disease duration, (typically 40-50 years for FRDA, compared with 20 years for Parkinson's disease), these figures may underestimate the true burden of the disease.

Conclusion: It is hoped that these estimates of resource utilization, can help in understanding the previously unquantified burden of FRDA. Given the long disease duration, management strategies should seek to minimise the impact of the condition on individuals and their caregivers, while maximising quality of life.

Keywords: Ataxia, Friedreich's Ataxia, Quality of life, Cost of illness, Resource utilization

\footnotetext{
* Correspondence: p.giunti@ucl.ac.uk

${ }^{1}$ Department of Molecular Neuroscience, UCL Institute of Neurology, Queen

Square, London WC1N 3BG, UK

Full list of author information is available at the end of the article
} 


\section{Background}

Friedreich's Ataxia (FRDA) is an autosomal recessive neurodegenerative disorder that causes progressive damage to both the central and peripheral nervous systems. Although rare, it is the most frequent of the inherited ataxias, with an estimated prevalence in Europe of 1 in 50,000 [1]. FRDA is caused by mutations in the gene encoding the protein frataxin on chromosome 9q13, most commonly in the form of a GAA expansion within the first intron of the gene, which causes decreased production of frataxin [2]. Current evidence suggests that a loss of frataxin causes iron overload in mitochondria and an increase in free-radical production leading to oxidative damage and inactivation of mitochondrial respiratory chain enzymes, particularly complexes I, II, III and aconitase [3].

FRDA is characterized by progressive gait and limb ataxia, dysarthria, dysphagia, abnormal eye movements, hearing problems, sensory loss, muscular weakness, areflexia and extensor plantar responses. Non-neurological features include scoliosis, foot deformity, hypertrophic cardiomyopathy and diabetes mellitus [4]. Symptom onset typically occurs in childhood or adolescence, although lateonset cases are described. Life expectancy is around 40-50 years [3-5].

The management of individuals with FRDA requires a multidisciplinary approach. Most people diagnosed with the disorder require mobility aids such as a cane, walker or wheelchair by their teens or early 20 s, and may require surgery for scoliosis or foot deformities [6]. Regular follow-up with annual echocardiograms and blood tests are necessary to detect and monitor the development of cardiac involvement and diabetes. Because of the progressive and disabling neurological and other features of the condition, FRDA has a significant impact upon quality of life [7].

Little or no data are available in the literature on the burden of FRDA on individuals with the condition, their families, caregivers, or society. More specifically, there is no record of previous investigations into resource utilisation by patients with FRDA. To address this gap the current questionnaire-based studies were conducted to collect information on the treatment and care of individuals with FRDA in the UK and Germany, and the burden of the disease on these individuals and their caregivers. Secondary objectives included a comprehensive description of people with FRDA (including their symptoms, diagnostic information and demographics), analysis of current management practices and treatment patterns.

Finally we compared the Cost of Illness (COI) of FRDA with Parkinson's disease, one of the most common neurodegenerative conditions and one with similarities in terms of symptoms and progression of the disease [8].

\section{Methods}

\section{Study design}

Cross-sectional observational studies were conducted in the UK and Germany to estimate the burden of FRDA on individuals with the condition and on the respective healthcare systems. Participants in both countries were asked to complete a Patient and Caregiver Information Form (PCIF), regarding access to, and use of, healthcare resources, and the impact FRDA has on their lifestyle. The PCIF was jointly developed by Adelphi Real World (ARW) and Takeda with additional scientific input being provided by Takeda, Ataxia UK and a leading German Neurologist with a special interest in neurodegenerative and hereditary movement disorders. In addition, the PCIF was reviewed by a patient with FRDA in terms of the form's ease of use, layout and font size, and the appropriateness of the questions/language used. All questions in the PCIF were closed questions.

For the purposes of this study, participants were considered to be children if aged 17 years and under, and adult if aged 18 years or over. In terms of who completed the PCIF, the parent or the child, children were encouraged to complete the form, with parental assistance if necessary. For very young children, the parent completed the form on their behalf. For individuals not capable of completing the PCIF, their caregivers were asked to complete selected sections of the questionnaire on their behalf.

Included in the PCIF were questions on patient demographics, FRDA medical history, healthcare resource utilization (hospitalizations, surgical procedures, consultation frequency, medications etc), loss of patient and caregiver productivity (Work and Productivity Impairment Index questionnaire - WPAI [9], the use of aids and adaptations, together with the impact FRDA has on their quality of life. In addition, patients were asked to provide details of the cost of any modifications made to their living accommodation, and how these modifications were paid for.

In the UK, individuals with the condition were recruited through the ataxia patient association, Ataxia UK, while in Germany, individuals were recruited by their physician. In the UK, Ataxia UK posted PCIFs to 200 patients randomly selected from Ataxia UK's database, along with an introductory letter and patient information sheet explaining the study.

In Germany, a total of 25 neurologists were approached to take part in the study, of whom 5 agreed to participate. These 5 neurologists working in specialist centres in Göttingen, Munich, Freiburg, Bonn and Essen, were asked to complete a Patient Record Form (PRF), using information collected from the medical record, for individuals with FRDA who had been under their supervision for at least two years. Included in the physician completed PRFs 
were questions on patient demographics, consultation history, Friedreich's Ataxia Rating Scale [10] score, activities of daily living, diagnostic tests, symptoms and medication history. Having completed the PRF, the neurologists were asked to post a corresponding PCIF, together with an instruction sheet, to each patient they included in the study so that the physician and patient-reported data could be linked. As in the UK study, no sensitive data were collected.

In Germany, information on direct medical resource use was provided by the physician as well as the participant. Information on diagnostic procedures was provided by the physician. Information on direct nonmedical resources (such as aids and adaptations) was collected from participants only. Both physician and participants were asked to provide details on respite care. Where information was supplied by both the physician and participant, data were collected from the medical record as these were deemed more reliable than those from participant recollection. For both the UK and Germany, consent was implicit in the return of the surveys.

In terms of the recall period, with the exception of questions such as "had they ever had surgery" or "did they use mobility and/or other aids", the recall period was 12 months. The recall period for work productivity was 7 days as this is the stated recall period for the Work Productivity and Activity Impairment (WPAI) tool.

The data were collated and analysed using STATA ${ }^{\circledR}$ Version 10 (StataCorp LP, College Station, USA) and SPSS $^{\circledR}$ Version 15 (SPSS Inc., Chicago, USA). As sample sizes were low in both the UK $(n=75)$ and Germany $(n=28)$, qualitative (i.e. the reporting of frequencies and percentages) rather than quantitative statistics, were conducted.

Resource utilization can be analysed from a number of perspectives. In this analysis, annual direct and indirect resource utilization and costs were calculated for the UK only. For the German study, analyses were conducted on direct and indirect resource utilization.

In terms of resource utilization, the following were considered in the analysis:

- Patient visits to various Health Care Professionals (HCPs) (neurologists, primary care physicians (PCPs), physiotherapists, nurses etc.) in the previous 12 months.

- Individuals with FRDA hospitalized in the previous 12 months for medical or surgical procedures.

- Diagnostic tests performed on patients in the previous 12 months (Germany only).

- Current medication - prescription and nonprescription.
- Modifications made by individuals with FRDA to their living accommodation.

- Mobility aids used by individuals with FRDA.

- Short-term or respite care used by individuals with FRDA.

- Formal and informal caregiving provided by professionals and caregivers related to the patient.

- For patients currently in employment/education, work/teaching-time missed as a consequence of FRDA.

- Patients currently unemployed or on benefit.

\section{UK cost of illness}

A bottom-up cost of illness methodology was employed; calculating costs on an individual basis before aggregating a total cost.

Costs were analysed in three main categories: (i) direct costs, (ii) costs associated with productivity and work loss and (iii) non-recurring (capital expenditure) costs. Direct costs were again divided into direct medical and other (non-treatment) direct costs. Direct medical costs included outpatient and community consultation costs, surgical and hospitalization costs, health-related service costs and medication costs, (including where appropriate, the cost of non-prescribed drugs). Other direct costs included social and respite care, and other non-treatment costs. Longer term costs such as mobility assistance and adaptations to living accommodation, realized over a number of years, were depreciated according to standard accountancy practices.

Unit cost data were obtained from published UK sources and applied to respondent estimates of resource use. Hospitalization costs were taken from the National Schedule of Reference Costs Year: '2008-09' - NHS Trusts Elective Inpatient HRG Data [11], while unit costs for outpatient consultations were taken from "Unit cost of health and social care" published by the PSSRU, University of Canterbury, UK 2009 [12]. Drug costs were sourced from the British National Formulary Number 59 [13].

Indirect costs included a loss of productivity associated with individuals with FRDA and their caregivers caused by absenteeism, an inability to work due to FRDA, and caregivers having to reduce their working hours.

A human capital approach was used to calculate productivity losses arising from reduced working time or caregiving whereby the mean time lost was multiplied by the average daily wage and by the number of working days per year (taken to be 220) in order to extrapolate to an annual cost. The average weekly income in the UK was taken to be $£ 456$ per week (Office for National Statistics, Labour Market Statistics, June 2010), which equates to an average daily income of $£ 91.20$ or $£ 12.16$ per hour assuming a 7.5 hour working day. 


\section{Ethical approval}

For the UK, approval was sought and obtained from Welwyn Clinical Pharmacology Ethics Committee to ensure the project met required ethical standards.

In Germany, ethical approval was obtained from the Ethical Committee of Göttingen or from the participating centre's local ethics committees.

\section{Results}

In the UK, questionnaires were sent to 200 individuals with FRDA. A total of 75 questionnaires were returned, with all 75 questionnaires being suitable for analysis; an overall response rate of 38\%. In Germany, Neurologists at 5 centres (Gottingen, Munich, Freiburg, Bonn and Essen) agreed to participate in the study, providing information on a total of 28 individuals with FRDA.

\section{Demographic and socio-economic characteristics}

The demographics and socio-economic characteristics of the study population are summarised in Table 1. The mean age of respondents was $32 \pm 18$ years (range 8-71) in the UK and $28 \pm 14$ years (range 8-56) in Germany. Sixty-seven percent of participants in the UK were adults aged 18 years and above, compared with $71 \%$ in Germany. Fifty-three percent in the UK and $61 \%$ in Germany lived with their parents while 35\% and 34\% respectively were in full time education. A higher proportion of female participants (52\% in the UK and 64\% in Germany) were recruited to the study. In Germany, the proportion of participants in full time employment was almost twice that of the UK (13\% compared with $7 \%$, while $30 \%$ of the study population were unemployed due to FRDA in the UK compared to $25 \%$ in Germany.

\section{Symptoms}

The mean age of symptom onset was $14.1 \pm 11.3$ years (range 2-63 years) and $11.3 \pm 6.1$ years (range 4-28 years) in the UK and Germany respectively. In the UK, $46 \%$ of individuals with FRDA first experienced symptoms as children aged up to 10 years, $39 \%$ in their teenage years and $10 \%$ aged between 21 and 30 . In the UK, only $5 \%$ of respondents first experienced after their 30th birthday. In Germany, 43\% first experienced FRDArelated symptoms as children aged up to 10 years, $43 \%$ as teenagers and $7 \%$ after their 21st birthday. (Note - 7\% of individuals in Germany did not know when they first experienced symptoms of FRDA The mean time from symptom onset to first doctor visit was $1.6 \pm 3.1$ years (range $0-19$ years) in the UK and $2.0 \pm 3.1$ years (range $0-10$ years) in Germany. The time from first doctor visit to diagnosis was $2.7 \pm 3.7$ years (range 0 - 20 years) in the UK and $1.9 \pm 2.3$ years (range $0-8$ years) in Germany.
With participants being asked to record all FRDArelated symptoms experienced over the previous 12 months, the results (Table 2) show participants experienced a range of symptoms linked to their condition including: stability and coordination problems, gait ataxia, scoliosis, foot and eye problems, fatigue, anxiety and depression, speech and swallowing difficulties, cardiac problems and diabetes.

\section{Resource utilization in United Kingdom}

In terms of health care resource utilization, a total of 17 UK participants (23\%) had been hospitalized in the

Table 1 Demographics and socioeconomic characteristics of participants with FRDA in the UK and Germany

\begin{tabular}{|c|c|c|}
\hline & $\begin{array}{l}\text { United } \\
\text { Kingdom }^{1}\end{array}$ & Germany ${ }^{2}$ \\
\hline \multirow[t]{3}{*}{ Mean Age (years) $\pm S D$} & $32 \pm 18$ & $28 \pm 14$ \\
\hline & (Range 8-71) & (Range 8-56) \\
\hline & $n=74$ & $n=28$ \\
\hline \multirow[t]{3}{*}{ Gender } & $\begin{array}{l}36(48 \%) \\
\text { Male }\end{array}$ & $\begin{array}{l}10(36 \%) \\
\text { Male }\end{array}$ \\
\hline & $\begin{array}{l}39(52 \%) \\
\text { Female }\end{array}$ & $\begin{array}{l}18(64 \%) \\
\text { Female }\end{array}$ \\
\hline & $n=75$ & $n=28$ \\
\hline Adults (aged > 18 years) & $50(67 \%)$ & $20(71 \%)$ \\
\hline \multirow[t]{2}{*}{ Children (aged <18 years) } & 25 (33\%) & 8 (29\%) \\
\hline & $\mathrm{n}=75$ & $n=28$ \\
\hline \multirow[t]{3}{*}{ Mean age of symptom onset } & $\begin{array}{c}14.1 \text { years } \\
( \pm 11.3 \text { years })\end{array}$ & $\begin{array}{l}11.3 \text { years } \\
( \pm 6.1)\end{array}$ \\
\hline & $\begin{array}{l}\text { Range } 2-63 \\
\text { years }\end{array}$ & $\begin{array}{c}\text { Range } 4-28 \\
\text { years }\end{array}$ \\
\hline & $\mathrm{n}=72$ & $n=26$ \\
\hline \multirow[t]{3}{*}{$\begin{array}{l}\text { Time from symptoms to first } \\
\text { doctor visit }\end{array}$} & $\begin{array}{c}1.6 \text { years } \\
( \pm 3.1 \text { years })\end{array}$ & $\begin{array}{l}2.0 \text { years } \\
( \pm 3.1)\end{array}$ \\
\hline & $\begin{array}{l}\text { Range } 0-19 \\
\text { years }\end{array}$ & $\begin{array}{l}\text { Range } 0-10 \\
\text { years }\end{array}$ \\
\hline & $\mathrm{n}=63$ & $n=27$ \\
\hline \multirow[t]{3}{*}{$\begin{array}{l}\text { Time from first doctor visit for } \\
\text { symptoms to diagnosis }\end{array}$} & $\begin{array}{c}2.7 \text { years } \\
( \pm 3.7 \text { years })\end{array}$ & $\begin{array}{l}1.9 \text { years } \\
( \pm 2.3)\end{array}$ \\
\hline & $\begin{array}{l}\text { Range } 0-20 \\
\text { years }\end{array}$ & $\begin{array}{l}\text { Range } 0-8 \\
\text { years }\end{array}$ \\
\hline & $n=66$ & $n=28$ \\
\hline \multirow[t]{2}{*}{ Living with their parents } & $40(53 \%)$ & $17(61 \%)$ \\
\hline & $n=75$ & $n=28$ \\
\hline \multirow{2}{*}{$\begin{array}{l}\text { In primary/secondary/higher } \\
\text { education }\end{array}$} & $26(35 \%)$ & $11(34 \%)$ \\
\hline & $n=74$ & $\mathrm{n}=32^{*}$ \\
\hline \multirow{2}{*}{$\begin{array}{l}\text { Employment status (\% employed } \\
\text { full time) }\end{array}$} & $5(7 \%)$ & $4(13 \%)$ \\
\hline & $n=74$ & $\mathrm{n}=32^{*}$ \\
\hline \multirow[t]{2}{*}{ Unemployed due to FRDA } & $22(30 \%)$ & $8(25 \%)$ \\
\hline & $n=74$ & $n=32^{*}$ \\
\hline
\end{tabular}

${ }^{1}$ Source UK - PCIF.

${ }^{2}$ Source Germany - PCIF.

*Multiple responses. 
Table 2 Participant reported symptoms experienced in the previous 12 months

\begin{tabular}{llc}
\hline Symptoms & $\begin{array}{c}\text { United Kingdom } \\
\mathbf{n}(\%)^{\mathbf{1}}\end{array}$ & $\begin{array}{c}\text { Germany } \\
\mathbf{n}(\%)^{\mathbf{2}}\end{array}$ \\
\hline $\begin{array}{l}\text { Gait / Posture symptoms } \\
\text { Problems with lower limb } \\
\text { coordination }\end{array}$ & $73(97 \%)$ & $23(82 \%)$ \\
\hline $\begin{array}{l}\text { Muscle weakness (upper or lower } \\
\text { limbs) }\end{array}$ & $68(91 \%)$ & $17(61 \%)$ \\
\hline $\begin{array}{l}\text { Problems with upper limb } \\
\text { coordination }\end{array}$ & $70(93 \%)$ & $18(64 \%)$ \\
\hline $\begin{array}{l}\text { Gait Ataxia (off balance when } \\
\text { walking) }\end{array}$ & $60(80 \%)$ & $18(64 \%)$ \\
\hline $\begin{array}{l}\text { Body sway when standing } \\
\text { Problems with standing upright }\end{array}$ & $63(84 \%)$ & $13(46 \%)$ \\
\hline $\begin{array}{l}\text { Muscle wasting (upper or lower } \\
\text { limbs) }\end{array}$ & $56(70 \%)$ & - \\
\hline Problems with sitting upright & $55(73 \%)$ & - \\
\hline Foot problems/deformities & $50(67 \%)$ & $15(54 \%)$ \\
\hline Scoliosis (curved spine) & $46(46 \%)$ & $20(71 \%)$ \\
\hline $\begin{array}{l}\text { Problems with sitting or standing } \\
\text { upright }\end{array}$ & - & $23(82 \%)$ \\
\hline
\end{tabular}

\section{Other Symptoms}

\begin{tabular}{lcc}
\hline Fatigue & $65(87 \%)$ & $21(75 \%)$ \\
\hline Slowness and slurring of speech & $62(83 \%)$ & $19(67 \%)$ \\
\hline Problems with swallowing & $51(68 \%)$ & 0 \\
\hline Anxiety & $39(52 \%)$ & $10(35 \%)$ \\
\hline Depression & $37(49 \%)$ & $7(25 \%)$ \\
\hline Problems with eye movements & $43(57 \%)$ & $8(28 \%)$ \\
\hline Palpitations & $31(41 \%)$ & $6(21 \%)$ \\
\hline Heart enlargement & $24(32 \%)$ & $9(32 \%)$ \\
\hline Other heart problems & $15(20 \%)$ & $5(17 \%)$ \\
\hline Difficulty breathing & $26(35 \%)$ & $6(21 \%)$ \\
\hline Loss of hearing & $25(33 \%)$ & $6(21 \%)$ \\
\hline Loss of sight & $22(29 \%)$ & $7(25 \%)$ \\
\hline Diabetes & $9(12 \%)$ & $4(14 \%)$ \\
\hline Heart failure & $5(7 \%)$ & $2(7 \%)$ \\
\hline
\end{tabular}

${ }^{1}$ Source UK - PCIF.

${ }^{2}$ Source Germany - PCIF.

previous 12 months. Of those admitted, the mean number of admissions was 2.6 (range 1-10 admissions) and the mean length of stay was 9.3 days. Respondents were asked to provide the reason for the most recent admission. Of the 15 people who provided a reason, three people were admitted for cardiovascular reasons, and three for diagnostic examinations.

Respondents were also asked to state the reason for admission for any previous hospitalizations within the last 12 months. Of the 40 responses, the most common reasons for admission were cardioversion (12.5\%), ECG / echocardiogram (7.5\% each), and routine heart examination / stabilization of diabetes ( $5 \%$ each). In all, heart related admissions (not diabetes) accounted for 16 of the 40 admissions (40\%).

In terms of surgical procedures, although none of the respondents had undergone foot surgery in the previous 12 months, 7 (9\%) had had foot surgery at some time. One patient reported having had spinal surgery (on two separate occasions), while 10 (13\%) reported having had spinal surgery at some time.

Respondents had an average of 14.12 consultations with health care professionals during the 12 month period; 5.09 consultations with doctors and 9.03 with other health care professionals. The most frequently consulted doctors were neurologists (61\%), followed by cardiologists (57\%) and PCPs (48\%). The mean number of consultations over the same period was 4.37 for PCPs, but only 1.55 and 1.34 for cardiologists and neurologists respectively. With regards to other health care professionals, the majority of consultations occurred with physiotherapists, nurses and occupational therapists with an average of 7.77, 3.95 and 2.94 consultations per annum respectively (Table 3 ).

In terms of medications, $50 \%$ of responders took an average of 2.97 prescribed medicines and 21\% purchased an average of 3.2 non-prescribed medications. Table 4 illustrates the most commonly prescribed and nonprescribed medications in the UK. Ten people (27\%) were prescribed idebenone, and a further 2 people $(14 \%)$ obtained it without prescription. Nine (24\%) and 8 (57\%) individuals respectively were either prescribed or purchased co-enzyme Q10, while a further 10 (27\%) and 7 (50\%) were either prescribed or purchased vitamin E. Other commonly prescribed prescription drugs including: beta-adrenoreceptor blocking agents, skeletal muscle relaxants and anti-epileptic drugs, were used by $24 \%, 19 \%$ and $16 \%$ of respondents respectively. Fish oils (omega 3 fatty acids) and other nutritional supplements, were used by $28 \%$ and $50 \%$ of respondents who purchased medications over the counter.

Table 5 illustrates the number of adults and children taking idebenone and co-enzyme Q10. Of the 75 UK respondents ( 25 children and 50 adults), 10 received prescribed idebenone, of which, 9 (12\%) were children. Of those purchasing idebenone without prescription, one was an adult $(1.3 \%)$ and another was a child (1.3\%). Of the 9 people (12\%) prescribed co-enzyme Q10, 6 (8\%) were children and of those purchasing the drug, 3 (4\%) were children and 5 (6.7\%) were adults.

In terms of social care, 19 respondents $(25 \%)$ received formal care from a professional caregiver providing on average 34.15 hours of care each week. Three people with FRDA had experienced respite/short-term care in the previous 6 months (averaging a total of 2.67 admissions per person with a mean stay of 3.5 days). 
Table 3 Consultations with health care professionals in the previous 12 months

\begin{tabular}{|c|c|c|c|c|}
\hline & $\begin{array}{l}\text { Consultations with HCPs } \\
\text { in the UK } n(\%)^{1}\end{array}$ & $\begin{array}{l}\text { UK - Mean number of } \\
\text { consultations with HCPs }{ }^{1}\end{array}$ & $\begin{array}{c}\text { Consultations with HCPs in } \\
\text { Germany } n(\%)^{2}\end{array}$ & $\begin{array}{l}\text { Germany - Mean number of } \\
\text { consultations with } \mathrm{HCPs}^{2}\end{array}$ \\
\hline \multicolumn{5}{|l|}{ Physicians } \\
\hline Neurologist & $46(61 \%)$ & 1.34 & $17(61 \%)$ & 1.71 \\
\hline $\begin{array}{l}\text { Cardiologist } \\
\text { (routine) }\end{array}$ & $43(57 \%)$ & 1.55 & $17(61 \%)$ & 0.75 \\
\hline PCP & $36(48 \%)$ & 4.37 & $17(61 \%)$ & 2.61 \\
\hline $\begin{array}{l}\text { Orthopaedic } \\
\text { specialist }\end{array}$ & $16(21 \%)$ & 1.37 & $13(46 \%)$ & 0.93 \\
\hline Paediatrician & $17(23 \%)$ & 2.47 & $4(14 \%)$ & 0.54 \\
\hline Psychiatrist & $5(7 \%)$ & 1.6 & $1(4 \%)$ & 0 \\
\hline \multicolumn{5}{|c|}{ Other Healthcare Professionals } \\
\hline $\begin{array}{l}\text { Occupational } \\
\text { therapist }\end{array}$ & $39(52 \%)$ & 2.94 & $10(36 \%)$ & 11.79 \\
\hline Physiotherapist & $35(47 \%)$ & 7.77 & $23(82 \%)$ & 28.07 \\
\hline $\begin{array}{l}\text { Nurse } \\
\text { practitioner }\end{array}$ & $21(28 \%)$ & 3.95 & $1(4 \%)$ & 0.14 \\
\hline $\begin{array}{l}\text { Speech } \\
\text { therapist }\end{array}$ & $17(23 \%)$ & 2.76 & $7(25 \%)$ & 9.93 \\
\hline Pharmacist & $9(12 \%)$ & 7.22 & $14(50 \%)$ & 3.43 \\
\hline
\end{tabular}

UK and Germany Compared.

${ }^{1}$ Source UK - PCIF.

${ }^{2}$ Source Germany - PRF.

Twenty-six people (35\%) were in primary, secondary or higher education, of whom 25 (21 children and 4 adults) required special educational support in the form of a classroom helper, a home tutor, a person to push their wheelchair or additional educational assistance.

Sixty-one percent of respondents had modified their living accommodation to ease the burden of FRDA. While extensive home improvements were the most expensive at an average of $£ 33,166$, the most common adaptations were changes to facilitate bathing at a mean cost of $£ 5,133$, and the provision of ramps at a mean cost of $£ 2,564$. The mean cost of other adaptations included: the widening of doors $(£ 1,911)$, the installation of hoists $(£ 1,684)$, electric beds $(£ 1,758)$ and mattresses (£627), changes to the flooring $(£ 1,561)$, stair rails $(£ 65)$ and a stair lift $(£ 1,197)$ (Table 6).

Funding for modifications to living accommodation and mobility aids can come from a number of sources. In the UK sources of funding included the National Health Service (NHS), Social Services, charitable grants and the respondents/families themselves. In terms of living accommodation, $37 \%$ of total costs were reimbursed by Social Services with $26 \%$ being paid for by the respondents themselves. Nine percent of costs were reimbursed by the NHS and $3 \%$ by charities. In contrast, the greatest proportion of costs related to

Table 4 Most commonly prescribed and non-prescribed (including over the counter and other) drugs used by FRDA respondents in the UK

\begin{tabular}{|c|c|c|}
\hline & Prescription drugs $(n=37)^{1}$ & Non-prescribed medication $(n=14)^{1}$ \\
\hline & n (\%) & n (\%) \\
\hline Idebenone & $10(27 \%)$ & $2(14 \%)$ \\
\hline Co-enzyme Q10 & $9(24 \%)$ & $8(57 \%)$ \\
\hline Vitamin E & $10(27 \%)$ & $7(50 \%)$ \\
\hline Beta-adrenoreceptor blocking agents (Atenolol, Bisoprolol, Propranolol) & $9(24 \%)$ & 0 \\
\hline Skeletal muscle relaxants & $7(19 \%)$ & 0 \\
\hline Anti-epileptic drugs & $6(16 \%)$ & 0 \\
\hline Fish oils (Omega 3 fatty acids) & 0 & $4(28 \%)$ \\
\hline Other nutritional supplements (Multivitamins, minerals etc) & 0 & $7(50 \%)$ \\
\hline
\end{tabular}

${ }^{1}$ Source UK - PCIF. 
Table 5 Number of children and adult respondents taking Anti-Oxidants in the UK and Germany

\begin{tabular}{|c|c|c|c|c|c|c|c|c|}
\hline & \multicolumn{2}{|c|}{ Prescription drugs (UK) ${ }^{1}$} & \multicolumn{2}{|c|}{ Non-prescription (UK) ${ }^{1}$} & \multicolumn{2}{|c|}{ Prescription drugs (Germany) $)^{2}$} & \multicolumn{2}{|c|}{ Non-prescription (Germany) } \\
\hline & Child & Adult & Child & Adult & Child & Adult & Child & Adult \\
\hline Idebenone & $9(12 \%)$ & $1(1.3 \%)$ & $1(1.3 \%)$ & $1(1.3 \%)$ & $5(17.9 \%)$ & $1(3.6 \%)$ & $3^{*}(10.7 \%)$ & $1^{*}(3.6 \%)$ \\
\hline Co-enzyme Q-10 & $6(8 \%)$ & $3(4 \%)$ & $3(4 \%)$ & 5 (6.7\%) & $0(0 \%)$ & 1 (3.6\%) & $0(0 \%)$ & $0(0 \%)$ \\
\hline
\end{tabular}

*For the same patients, physician stated as prescription medication.

$\mathrm{n}=75$ for the UK ( 25 children and 50 adults).

$\mathrm{n}=28$ for Germany (8 children and 20 adults).

${ }^{1}$ Source UK - PCIF.

${ }^{2}$ Source Germany - PRF.

${ }^{3}$ Source Germany - PCIF.

mobility were reimbursed by the NHS (35\%), $12 \%$ by Social Services, with respondents paying 33\% themselves and charities $15 \%$.

FRDA has an indirect cost that can be measured in an individual's productivity at, and absenteeism from, work and the reduction in working hours required by the caregiver to help the person with FRDA. Thirteen percent of people with FRDA were in paid employment, working a mean of 23.6 hours per week. The mean time lost for those currently employed was 1 hour per week. For those attending classes, they spent an average of 24.8 hours per week in class, and missed an average of 3.9 hours. Seventy-seven percent of respondents required caregiver support. Eight of the 58 caregivers (14\%) were professional caregivers. Twenty-nine percent and $19 \%$ of caregivers were in full or part-time employment. Twenty-two percent of caregivers had had to take time off work to care for the person with FRDA. On average, caregivers had a mean time off work of 26.15 hours per week.

\section{Resource utilization in Germany}

In Germany, 13 participants, or $46 \%$, had been hospitalized for FRDA-related symptoms in the previous 12 months. The mean length of stay was 5.2 days.

Table 6 Total cost and funding source for home modifications and aids used by UK respondents ${ }^{1}$

\begin{tabular}{|c|c|c|c|c|c|c|}
\hline Modification & Total cost $(£)$ & NHS (£) & Social services $(£)$ & Out-of-pocket (£) & Not stated & Mean cost of adaptation ( $(£)$ \\
\hline \multirow[t]{2}{*}{ Adaptation bath/ shower } & 189,927 & 12,219 & 105,760 & 55,305 & 16,643 & 5,133 \\
\hline & & $(6.4 \%)$ & $(55.7 \%)$ & $(29.1 \%)$ & $(8.8 \%)$ & \\
\hline \multirow[t]{2}{*}{ Changes to home flooring } & 21,850 & 0 & 1,900 & 13,950 & 6,000 & 1,561 \\
\hline & & & $(8.7 \%)$ & $(63.8 \%)$ & $(27.5 \%)$ & \\
\hline \multirow[t]{2}{*}{ Door Widening } & 34,408 & 1,775 & 17,431 & 7,426 & 7,776 & 1,911 \\
\hline & & $(5.2 \%)$ & $(50.7 \%)$ & $(21.6 \%)$ & $(22.6 \%)$ & \\
\hline \multirow[t]{2}{*}{ Electric bed } & 33,407 & 13,264 & 5,350 & 9,550 & 5,243 & 1,758 \\
\hline & & $(39.7 \%)$ & $(16.0 \%)$ & $(28.6 \%)$ & $(15.7 \%)$ & \\
\hline \multirow[t]{2}{*}{ Hand rail \& Grab rail } & 1,277 & 290 & 697 & 0 & 290 & 256 \\
\hline & & $(22.7 \%)$ & $(54.6 \%)$ & & $(22.7 \%)$ & \\
\hline \multirow[t]{2}{*}{ Hoist } & 32,000 & 5,600 & 25,600 & 0 & 800 & 1,684 \\
\hline & & $(17.5 \%)$ & $(80 \%)$ & & $(2.5 \%)$ & \\
\hline \multirow[t]{2}{*}{ Ramps } & 76,933 & 4,433 & 49,967 & 18,000 & 4,533 & 2,564 \\
\hline & & $(5.8 \%)$ & $(64.9 \%)$ & $(23.4 \%)$ & $(5.9 \%)$ & \\
\hline \multirow[t]{2}{*}{ Specialized Mattress } & 9,400 & 5,400 & 600 & 2,800 & 600 & 627 \\
\hline & & $(57.4 \%)$ & $(6.4 \%)$ & $(29.8 \%)$ & $(6.4 \%)$ & \\
\hline \multirow[t]{2}{*}{ Stair Lift } & 5,985 & 1,500 & 995 & 1,500 & 0 & 1,197 \\
\hline & & $(37.5 \%)$ & $(24.9 \%)$ & $(37.5 \%)$ & & \\
\hline \multirow[t]{2}{*}{ Stair rail } & 786 & 327 & 131 & 262 & 65 & 65 \\
\hline & & $(41.7 \%)$ & $(16.7 \%)$ & (33.4\%) & $(8.3 \%)$ & \\
\hline \multirow[t]{2}{*}{ Extensive home improvement } & 199,000 & 0 & 143,000 & 11,000 & 45,000 & 33,166 \\
\hline & & & $(71.9 \%)$ & $(5.5 \%)$ & $(22.6 \%)$ & \\
\hline
\end{tabular}

${ }^{1}$ Source UK - PCIF. 
In terms of surgical procedures, while none of the respondents had undergone foot surgery in the previous 12 months, $21 \%$ had had surgery in the past. Overall $15 \%(n=27)$ had had spinal surgery at some time.

The majority of participants (61\%) had consulted a neurologist in the previous 12 months, 61\% a cardiologist, and $61 \%$ a PCP; seeing these doctors an average of $1.71,0.75$ and 2.61 times respectively. In terms of other health care professionals, the majority of consultations occurred with physiotherapists (82\% of respondents), followed by occupational therapists (36\%) and speech therapists (25\%); seeing each an average of 28.07, 11.79 and 9.93 times respectively (Table 3).

Participants also provided details on health-related service utilization including the type of service, total cost and mode of reimbursement. Of the 28 participants, 6 (21\%) reported using a health-related service. Eightytwo percent of respondents visited a physiotherapist at least once in the previous 12 months, but only $11 \%$ of patients provided details on reimbursement. In terms of health-related services, most were reimbursed by mandatory health insurance or paid for by the respondent. Of the 6 respondents who provided reimbursement details for chiropody, hippotherapy, physiotherapy and pilates, total costs equated to $€ 1,445$, of which $5 \%$ were paid for by mandatory health insurance, $28 \%$ by private health insurance and $67 \%$ by the respondent.

In terms of drug therapy, $64 \%$ of German participants took prescribed medication for FRDA-related symptoms, an average of 2.2 drugs per patient per annum. The most commonly prescribed drugs were idebenone (33\%), betaadrenoreceptor antagonists (22\%), muscle relaxants (22\%) and non-steroidal anti-inflammatory drugs (NSAID's)
(17\%). Twenty-nine percent of participants reported utilizing non-prescribed medications; purchasing an average of 1.38 drugs for FRDA-related symptoms. The eight drugs bought without prescription were idebenone, Cranberola, Magnesium, L-carnitine, Cuprum Metallicum D6, Plumbum D6, Captobeta and Ranitidine.

Neurological testing was conducted at least once on all participants and included the Scale for the Assessment and Rating of Ataxia (SARA), the International Cooperative Ataxia Rating Scale (ICARS) and the Friedreich's Ataxia Rating Scale (FARS). In addition, physicians conducted a number of diagnostic tests at regular intervals. These tests included: blood pressure, electrocardiograms, lipid profiles, echocardiograms, glucose tests, HbA1c, liver and kidney function tests, hearing and eye tests, spinal radiographs and MRI scans.

In terms of non-medical resource use, $7 \%$ of patients had used short-term respite care in the previous 12 months and of the 12 in an academic setting, 8 received special educational services. Sixteen participants (57\%) had modified their accommodation to support their daily living. With a mean of 3.1 modifications per participant, the most common adaptations were modifications to the bath and shower facilities (63\%), the fitting of handles/ handrails (44\%) and the installation of a lifter/hoist (31\%) - (Table 7). With the source of funding for these adaptations being reported by the respondents themselves, Table 8 shows a total cost of $€ 7,252$ for home adaptations and aids excluding cars, (or €45,252 including the cost of cars), of which the majority was met through mandatory health insurance.

In terms of productivity lost in the previous 7 days, employed participants missed an average of 1.9 hours of

Table 7 Modifications to living accommodation made by German respondents ${ }^{1}$

\begin{tabular}{|c|c|c|c|c|c|}
\hline \multirow[b]{2}{*}{ Modification (n) } & \multirow[b]{2}{*}{ Proportion } & \multicolumn{4}{|c|}{ Reimbursement sources for home adaptations / aids } \\
\hline & & $\begin{array}{l}\text { Mandatory health insurance } \\
n(\%)\end{array}$ & $\begin{array}{l}\text { Private health insurance } \\
\mathrm{n}(\%)\end{array}$ & $\begin{array}{l}\text { Out of pocket } \\
n(\%)\end{array}$ & $\begin{array}{l}\text { Not stated } \\
\text { n (\%) }\end{array}$ \\
\hline Adapted bath/shower (10) & $63 \%$ & $6(60)$ & $1(10)$ & 0 & $3(30)$ \\
\hline Bathroom alterations (4) & $25 \%$ & $3(75)$ & 0 & 0 & $1(25)$ \\
\hline Kitchen alterations (1) & $6 \%$ & 0 & 0 & $1(100)$ & 0 \\
\hline Adapted bed (4) & $25 \%$ & $3(75)$ & 0 & 0 & $1(25)$ \\
\hline Electric wheelchair (3) & $19 \%$ & $3(100)$ & 0 & 0 & 0 \\
\hline Handles/rails (7) & $44 \%$ & $4(57)$ & 0 & $1(14)$ & $2(29)$ \\
\hline Lifter/Hoist (5) & $31 \%$ & $5(100)$ & 0 & 0 & 0 \\
\hline Ramp (4) & $25 \%$ & $3(75)$ & $1(25)$ & 0 & 0 \\
\hline Speaking computer (1) & $6 \%$ & $1(100)$ & 0 & 0 & 0 \\
\hline Walking frame (1) & $6 \%$ & $1(50)$ & 0 & 0 & 0 \\
\hline Walking sticks (1) & $6 \%$ & 0 & 0 & $1(100)$ & 0 \\
\hline Wheel chair (3) & $19 \%$ & $2(67)$ & 0 & 0 & $1(33)$ \\
\hline Other* (7) & $44 \%$ & $1(14)$ & 0 & $1(14)$ & $5(72)$ \\
\hline
\end{tabular}

* Adaptation to house, folding chair, mattress, special seat, cars.

${ }^{1}$ Source Germany - PCIF. 
Table 8 Total cost and funding source for home modifications and aids used by German respondents ${ }^{1}$

\begin{tabular}{|c|c|c|c|c|c|}
\hline Modification & Total cost $(€)$ & Mandatory health insurance $(€)$ & Private health insurance(€) & Out-of-pocket $(€)$ & Not stated \\
\hline Adapted bath/shower & 135 & 43 & 29 & 15 & 48 \\
\hline Alteration of bath room & 436 & 182 & 0 & 182 & 73 \\
\hline Alteration of kitchen & 364 & 0 & 0 & 364 & 0 \\
\hline Adapted bed & 800 & 600 & 0 & 0 & 200 \\
\hline Electric wheelchair & 2,400 & 2,400 & 0 & 0 & 0 \\
\hline Handles/rails & 54 & 33 & 0 & 2 & 20 \\
\hline Lifter & 800 & 800 & 0 & 0 & 0 \\
\hline Ramp & 239 & 216 & 23 & 0 & 0 \\
\hline Speaking computer & 364 & 364 & 0 & 0 & 0 \\
\hline Walking frame & 240 & 120 & 0 & 0 & 0 \\
\hline Walking sticks & 120 & 0 & 0 & 120 & 0 \\
\hline Wheelchair & 1,200 & 800 & 0 & 0 & 400 \\
\hline Mattress & 100 & 0 & 0 & 100 & 0 \\
\hline Cars & 38,000 & 0 & 0 & 0 & 38,000 \\
\hline \multirow[t]{2}{*}{ Total (excluding cars) } & 45,252 & 5,557 & 52 & 902 & 38,741 \\
\hline & $(7,252)$ & $(5,557)$ & $(52)$ & $(902)$ & $(741)$ \\
\hline
\end{tabular}

${ }^{1}$ Source Germany - PCIF.

work, while those in education missed an average of 5 hours of classes.

In terms of care, $60 \%$ of German participants required caregiver support to complete their daily activities. Fifty nine percent of all primary caregivers were the parents (and in particular the mother - 80\%), 18\% were professional carers, $18 \%$ partners and $6 \%$ other relatives. Caregivers per se provided a mean of $7 \mathrm{~h}$ of support each week of which the individual's partners provided $7 \mathrm{~h}$, the parent $4 \mathrm{~h}$, other relatives $9 \mathrm{~h}$ and professional caregivers 16.7 h. Two caregivers reported having reduced their working hours by an average of $2.5 \mathrm{~h}$ per week in order to provide care.

\section{Annual cost of illness in United Kingdom}

In terms of cost of illness (Table 9), the direct-medical costs incurred in caring for the 75 individuals with FRDA in the UK totaled $£ 242,314$ per annum. This figure, split between hospitalization costs $(£ 50,067)$, consultation costs $(£ 71,888)$, and medication costs $(£ 120,359)$, gave a mean cost per respondent of $£ 3,230$. Non-direct medical costs of $£ 322,940$ per annum, were comprised of educational

Table 9 Total annual direct medical and non-medical costs of FRDA in the United Kingdom (n=75)

\begin{tabular}{|c|c|c|}
\hline Direct medical cost & Cost & Proportion of total direct medical cost \\
\hline Hospitalizations & $£ 50,067$ & $21 \%$ \\
\hline Community / Outpatient Consultations & $£ 71,888$ & $30 \%$ \\
\hline Prescription Medications & $£ 83,456$ & $34 \%$ \\
\hline Non-prescription Medications & $£ 36,903$ & $15 \%$ \\
\hline Total direct medical cost & $£ 242,314$ & \\
\hline Direct non-medical cost & Cost & Proportion of Total Direct Non- Medical Cost \\
\hline Educational Support & $£ 14,688$ & $4.5 \%$ \\
\hline Respite Care & $£ 3,584$ & $1.1 \%$ \\
\hline Professional Caregiver Support & $£ 304,668$ & $94.3 \%$ \\
\hline Total direct non-medical cost & $£ 322,940$ & \\
\hline Direct non-medical cost including long term adaptation and mobility costs & Cost & Proportion of total direct non-medical costs \\
\hline Modification / Adaptation & $£ 44,268$ & $10.43 \%$ \\
\hline Mobility & $£ 57,419$ & $13.52 \%$ \\
\hline Total direct non-medical cost with long term costs & $£ 424,627$ & \\
\hline Total direct cost excluding modification and mobility costs & $£ 565,254$ & \\
\hline Total direct cost including modification and mobility costs & $£ 666,941$ & \\
\hline
\end{tabular}


support costs $(£ 14,688)$, respite care costs $(£ 3,584)$ and professional caregiver costs $(£ 304,668)$; averaging $£ 4,306$ per respondent. The total annual direct cost of caring for people with FRDA was therefore $£ 565,254$ (mean cost $£ 7,537)$. Taking into account respondent reported expenses including living accommodation modifications $(£ 44,268)$ and mobility aids $(£ 57,419)$, the total annual direct non-medical cost of FRDA was $£ 666,941$.

Annual indirect costs resulting from a loss of respondent and caregiver productivity were estimated at $£ 4,426$ and $£ 214,989$ respectively, a total of $£ 219,415$. Taking into account potential work loss caused by respondents being unable to work long-term, this estimated total cost rose to $£ 741,079$ (Table 10).

Based on the responses received, FRDA resulted in a total annual cost of between $£ 886,356$ and $£ 1,408,020$ in the UK depending on whether the costs of long term unemployment due to FRDA $(£ 521,664)$ were included or not (Tables 11 and 12). These equated to a cost per person of $£ 11,818$ and $£ 18,774$ respectively.

\section{Discussion}

This study is the first to examine systematically the burden of FRDA in the UK and Germany, encompassing not only medical resource utilization, but also the burden on respondents in terms of symptoms, the impact on daily activities (including the need for mobility assistance and modifications to accommodation), and the requirement for caregiver support. The impact of caring for people with FRDA was also assessed.

The results show that the annual burden of FRDA is significant and falls on the health and social care sectors, on society due to work loss, on caregivers and on the individuals themselves. While the results of the UK COI study show a mean cost of health care per person of $£ 3,230$ per annum (including medications), this does not reflect the true burden of FRDA. When non-health care resource requirements (education, caregiver support etc) are included, the cost significantly rises to an estimated $£ 7,537$ per person. When indirect costs such as work loss, mobility aids and accommodation modifications are also taken into consideration, the estimated cost per person rises to between $£ 11,818$ and $£ 18,774$, depending on whether the costs of long-term unemployment or early

Table 10 Total annual indirect costs of FRDA in the United Kingdom ( $\mathbf{n} \mathbf{5 0}$ adults)

\begin{tabular}{lc}
\hline & Cost \\
\hline Respondent related costs (time off work) & $£ 4,426$ \\
\hline Respondent related costs (unable to work due to FRDA) & $£ 521,664$ \\
\hline Caregiver related costs & $£ 214,989$ \\
\hline Total costs excluding unemployment due to FRDA & $£ 219,415$ \\
\hline Total costs including unemployment due to FRDA & $£ 741,079$ \\
\hline
\end{tabular}

Table 11 Total Cost of Friedreich's Ataxia (including long term unemployment) in the United Kingdom $(n=75)$

\begin{tabular}{|c|c|c|}
\hline & Cost & Proportion of total cost \\
\hline Direct Treatment Costs & $£ 242,314$ & $17 \%$ \\
\hline Direct Non-Treatment Costs & $£ 424,627$ & $30 \%$ \\
\hline Work Loss $^{1}$ & $£ 741,079$ & $53 \%$ \\
\hline Total Cost & $£ 1,408,020$ & \\
\hline
\end{tabular}

${ }^{1}$ Work Loss sample size $=50$ adults.

retirement due to FRDA are included in the calculation. As direct health care costs represent such a small proportion of total costs, focussing on these and excluding the cost of long-term unemployment, would significantly underestimate the true burden to society. The main benefits of improved treatment options would be felt from a societal perspective should the need for caregiver support be reduced, if people were more able to participate in the workforce and if the need for modifications to living accommodation were reduced.

In terms of resource utilization, $61 \%$ of participants visited a neurologist in the UK and in Germany, while $47 \%$ and $82 \%$ visited a physiotherapist, and $48 \%$ and $61 \%$ a PCP, (UK and Germany respectively).

In Germany, the proportion of patients admitted to hospital for FRDA in the previous 12 months was twice that in the UK (46\% versus $23 \%$ ). Similarly, the proportion of participants who had had foot surgery at some time was more than double that in the UK $(21 \%$ versus 9\%), while non-prescribed drug use for FRDA-related symptoms was higher in the UK (3.2 versus 1.38 medications). The apparent difference in co-enzyme Q10 use between the two countries is notable with just one German patient taking co-enzyme Q10, compared with 17 (9 prescription and $8 \mathrm{OTC}$ ) in the UK. This difference may in part be a consequence of a high dose co-enzyme Q10/vitamin E trial having been conducted in the UK [14] and may also reflect a bias in the UK sample of patients. In general, patients willing to fill in questionnaires are more willing to participate in research and therefore more active in seeking therapeutic options.

Among the employed participants, mean work-time lost per patient was higher in Germany than in the UK (1.9 versus 1 hour per week), while the proportion of UK caregivers who had had to take time off work was almost twice that of Germany (22\% versus $12 \%$ ).

Table 12 Total cost of Friedreich's Ataxia (excluding long term unemployment) in the United Kingdom $(n=75)$

\begin{tabular}{llc}
\hline & Cost & Proportion of total cost \\
\hline Direct Treatment Costs & $£ 242,314$ & $27 \%$ \\
\hline Non-Treatment Costs & $£ 424,627$ & $48 \%$ \\
\hline Work Loss $^{1}$ & $£ 219,415$ & $25 \%$ \\
\hline Total Cost & $£ 886,356$ & \\
\hline${ }^{1}$ Work Loss sample size $=50$ adults.
\end{tabular}

${ }^{1}$ Work Loss sample size $=50$ adults. 
In interpreting these data, a number of caveats should be considered including the sample size. With 75 UK and 28 German patients taking part in the study, it is not possible to say whether they were representative of the FRDA populations although, considering the rarity of the condition, these sample sizes are considered reasonable.

The differing means of recruitment should also be taken into account. UK respondents could be more highly motivated (since they were known to the patient association and took the time to complete the questionnaire). While this is not a problem in itself, there is potential to introduce bias if these patients were atypical in terms of disease severity or in their ability to access health and social care resources.

Similarly the methodological differences between the two samples should be considered: whereas in the UK respondents were asked to complete PCIFs from memory, in Germany, in addition to the PCIFs completed by the patients, the recruiting physicians collected resource use and diagnostic information on PRFs. No such physician-reported, treatment-related data were collected in the UK study.

While patient recall is likely to be reasonable over the last 3 months, it may be less accurate (especially for routine events) as the recall period increases. Exceptions are major events such as hospitalizations and surgery, where there is evidence to suggest recall is as good over longer periods of time. While the recall periods specified in the questionnaires were designed to reflect this, an element of recall bias cannot be ruled out.

With no comprehensive studies in the literature, direct comparisons are difficult. For this reason we have chosen to compare the mean annual burden of FRDA with that of Parkinson's disease, one of the most common neurodegenerative conditions and one with similarities in terms of symptoms and progression of the disease [8].

Findley et al reported a higher mean annual burden for advanced Parkinson's disease of $£ 28,700$ [8], compared with between $£ 11,818$ and $£ 18,774$ for FRDA. Of the $£ 28,700$, $£ 1,881$ could be attributed to direct medical costs, $£ 13,364$ to direct non-medical costs and $£ 12,454$ to indirect informal care cost. Thirty-nine percent of advanced Parkinson's disease patients were hospitalized in the previous 12 months, compared with $23 \%$ of individuals with FRDA in the UK and 46\% in Germany. Parkinson's disease patients experienced an average of 1.6 admissions and 2.9 consultations per year, while in the UK, individuals with FRDA experienced 2.6 admissions and 14.1 consultations. In terms of direct non-medical resources such as respite care, $13 \%$ of Parkinson's disease patients had used respite care in the previous 12 months, compared with 5\% of FRDA responders in the UK and 7\% in Germany.
Parkinson's disease severity is measured using the Hoehn and Yahr (H\&Y) scale. All Parkinson's disease patients, regardless of disease severity, can experience the OFF state. In the OFF state, individuals with Parkinson's disease can experience tremors, stiffness, slowness of movement and/or periods of immobility. This can be due to medication wearing off, or a reaction to the medication itself, manifesting in a re-emergence of symptoms.

Sixty-eight percent of people with Parkinson's disease reported in the study by Findley had a $(H \& Y)$ score of 3 or 4 , spending between 0 and $25 \%$ of their waking time in an OFF state (=OFF 1). As expected, disease progression was associated with an increase in carer hours from 5.4 professional and 34 informal carer hours/week for OFF 1 , to 21 professional and 51.25 informal care hours/ week for OFF IV.

In contrast to Findley's study, where the average age of individuals with Parkinson's disease was 71.7 years, the average age of individuals with FRDA was significantly less at 32 years in the UK and 28 in Germany. With more children and young adults in the early to midstages of the disease, the cost of care is lower and may well be hidden (with younger parents, individuals with FRDA potentially have access to additional informal unpaid support from relatives, teachers and other caregivers). Given that Parkinson's disease has a duration of 20 years whereas FRDA has a duration of 40 to 50 years, the cost to society may well be greater than for Parkinson's disease.

In terms of future work, studies could include validating the PCIF for use in other countries and incorporating the use of the Friedreich's Ataxia Impact Scale (FAIS) [15]. Data from the FAIS could then be compared to actual costs and burden of care to give an indication of the impact of the disease. Similarly, collecting data on clinical parameters such as the Friedreich's Ataxia Rating Scale (FARS) may provide an indication of the cost and burden associated with disease severity.

\section{Conclusions}

In conclusion it can be seen that the annual burden of FRDA is significant, falling on the health and social care sectors, on society (due to work loss), on caregivers, and on the individuals themselves. It is hoped that these estimates of resource utilization, from both a health sector and societal perspective, can help in understanding the previously unquantified burden of FRDA.

\section{Abbreviations}

FRDA: Friedreich's Ataxia; COI: Cost of Illness; PCIF: Patient and Caregiver Information Form; ARW: Adelphi Real World; WPAl: Work and Productivity Impairment Index questionnaire; PRF: Patient Record Form; HCP: Health Care Professional; PCP: Primary Care Physician; OTC: Over the counter; NHS: National Health Service; SARA: Scale for the Assessment and Rating of 
Ataxia; ICARS: International Cooperative Ataxia Rating Scale; FARS: Friedreich's Ataxia Rating Scale.

\section{Competing interests}

The authors declare that they have no competing interests. Dr Paola Giunti received no financial compensation for her work on the project.

\section{Authors' contributions}

PG - Reviewed the Patient and Caregivers Information Form and reviewed and revised the manuscript for intellectual content. JG - Was involved in the design of the Patient and Caregivers Information form and reviewed the manuscript. AS - Was involved in the design of the Patient and Caregivers Information form and reviewed the manuscript. MP - Reviewed the manuscript. $\mathrm{JH}$ - Was involved in the study design, the development of the Patient and Caregivers Information form, Patient Record Form, co-ordination of the project and in reviewing the manuscript. RS - Was involved in coordination of the project and in reviewing the manuscript. JP - Was involved in the study design and in reviewing the manuscript. JO' $\mathrm{H}-$ Was involved in analysis of the data and reviewing the manuscript. LRC - Was involved in analysis of the data and reviewing the manuscript. FMS - Was involved in the study design, the development of the Patient and Caregivers Information form, Patient Record Form, co-ordination of the project and in writing the manuscript. All authors read and approved the final manuscript.

\section{Acknowledgements}

The study was sponsored by Takeda. The authors wish to acknowledge the following individuals for their contributions and critical review during the development of this manuscript: Peter Anderson from Adelphi Real World, Macclesfield, UK; Marisha Palm, a past employee of Adelphi Real World, Francis Pang, a past employee of Takeda Global Research and Development, Europe; Susan McCutcheon, a past employee of Takeda UK; and Professor Barry Hunt, Ataxia UK Trustee. Dr Paola Giunti's work was undertaken at University College London Hospitals/University College London, which received a proportion of funding from the Department of Health's National Institute for Health Research Biomedical Research Centres funding scheme. Dr Paola Giunti has received funding from the European Community under the 7th Framework Program (grant number

\section{3/EFACTS)}

\section{Author details}

${ }^{1}$ Department of Molecular Neuroscience, UCL Institute of Neurology, Queen Square, London WC1N 3BG, UK. ' Ataxia UK, 1-3 Brixton Road, London, UK. ${ }^{3}$ Takeda Pharmaceuticals Europe Ltd, 61 Aldwych, London, UK. ${ }^{4}$ Takeda Pharma GmbH, Aachen, Germany. ${ }^{5}$ Adelphi Real World, Bollington, Cheshire, UK.

Received: 10 October 2012 Accepted: 16 January 2013

Published: 28 February 2013

\section{References}

1. Cossée M, Schmitt M, Campuzano V, Reutenauer L, Moutou C, Mandel JL, et al: Evolution of the Friedreich's ataxia trinucleotide repeat expansion: Founder effect and permutations. Proc Natl Acad Sci 1997, 94:7452-7.

2. Lodi R, Tonon C, Calabrese V, Schapira AH: Friedreich's ataxia: from disease mechanisms to therapeutic interventions. Antioxid Redox Signal 2006, 8(3-4):438-43.

3. Schulz JB, Boesch S, Bürk K, Dürr A, Giunti $P$, Mariotti $C$, et al: Diagnosis and treatment of Friedreich's Ataxia: a European perspective. Nat Rev Neurosci 2009, 5(4):222-34.

4. Pandolfo M: Friedreich's Ataxia: the clinical picture. J Neurol 2009, 256(Suppl 1):3-8.

5. Tsou AY, Paulsen EK, Lagedrost SJ, Perlman SL, Mathews KD, Wilmot GR, Ravina B, Koeppen AH, Lynch DR: Mortality in Friedreich ataxia. J Neurol Sci 2011, 307(1-2):46-9.

6. Milbrandt TA, Kunes JR, Karol LA: Friedreich's Ataxia and Scoliosis: the experience at two institutions. J Pediatr Orthop 2008, 28(2):234-8.

7. Wilson CL, Fahey MC, Corben LA, Collins VR, Churchyard AJ, Lamont PJ, et al: Quality of life in Friedreich ataxia: what clinical, social and demographic factors are important? Eur J Neurol 2007, 14(9):1040-7.
8. Findley L, Wood E, Lowin J, Roeder C, Bergman A, Schifflers M: The economic burden of advanced Parkinson's disease: an analysis of a UK patient dataset. J Med Econ 2011, 14(1):130-139.

9. Reilly MC, Zbrozek AS, Dukes E004D: The validity and reproducibility of a work productivity and activity impairment instrument. Pharmaco Economics 1993, 4(5):353-365.

10. Subramony SH, May W, Lynch D, Gomez C, Fischbeck K, Hallett M, Taylor P, Wilson R, Ashizawa T: Cooperative Ataxia Group Measuring Friedreich ataxia: interrater reliability of a neurologic rating scale. Neurology 2005, 64(7):1261-2.

11. Department of Health: NHS reference costs. 2009. http://www.dh.gov.uk/en/ Publicationsandstatistics/Publications/PublicationsPolicyAndGuidance/ DH_111591.

12. Curtis L, Netten A: Unit costs of health and social care. University of Kent at Canterbury: Personal Social Services Research Unit; 2006.

13. British National Formulary 59 March 2010. British Medical Association: Pharmaceutical Press; ISBN-10:0853699293.

14. Cooper JM, Korlipara LVP, Hart PE, Bradley JL, Schapira AHV: Coenzyme Q10 and vitamin E deficiency and Friedreich's Ataxia: predictor of efficacy of vitamin E and coenzyme Q10 therapy. Eur J Neurol 2008, 15:1371-1379.

15. Cano SJ, Riazi A, Schapira AHV, et al: Friedreich's ataxia impact scale: a new measure striving to provide the flexibility required by today's studies. Mov Disord 2009, 24(7):984-992.

doi:10.1186/1750-1172-8-38

Cite this article as: Giunti et al:: Impact of Friedreich's Ataxia on healthcare resource utilization in the United Kingdom and Germany. Orphanet Journal of Rare Diseases 2013 8:38.

\section{Submit your next manuscript to BioMed Central and take full advantage of:}

- Convenient online submission

- Thorough peer review

- No space constraints or color figure charges

- Immediate publication on acceptance

- Inclusion in PubMed, CAS, Scopus and Google Scholar

- Research which is freely available for redistribution

Submit your manuscript at www.biomedcentral.com/submit 